DOI 10.37882/2223-2982.2020.07-2.04

\title{
ГЛАВНЫЕ ЧЛЕНЫ ПРЕДЛОЖЕНИЯ. ПРОБЛЕМА ВЫДЕЛЕНИЯ ПРЯМОГО ДОПОЛНЕНИЯ КАК ГЛАВНОГО ЧЛЕНА ПРЕДЛОЖЕНИЯ В СОВРЕМЕННОМ ИНГУШСКОМ ЯЗЫКЕ
}

\section{MAIN MEMBERS OF THE OFFER. THE PROBLEM OF DISTINGUISHING THE DIRECT COMPLEMENT AS THE MAIN MEMBER OF A SENTENCE IN MODERN INGUSH}

\section{A. Bogatyreva}

Summary: In this article, the author considers the theories of selecting the main members of the sentence in relation to the system of modern Ingush language. The point of view of linguists, according to which the direct complement is singled out as the main member of the sentence in the modern Ingush language, is questioned. The results obtained showed that the direct complement in this language is incorrectly assigned to the main members of the sentence. The examples also show how the subject can be expressed in the Ingush language.

Keywords: Ingush language, subject, predicate, direct complement, sentence, theories, sentence members.
Некоторые вопросы, связанные с синтаксисом ингушского языка, относятся к числу сложных и не до конца рассмотренных. Определение придаточных конструкций в сложноподчиненном предложении, выделение прямого дополнения как главного члена предложения и т.п. относятся к спорным вопросам данного языка.

Данная статья посвящена проблеме выделения главных членов предложения в современном ингушском языке.

Актуальность статьи обосновывается недостаточностью исследования вопросов изучения структуры и семантики предложения, а также наличие разных точек зрения на исследуемую проблему.

Цель - исследовать главные члены предложения ингушского языка.

\section{Задачи исследования:}

- рассмотреть различные точки зрения на данную тему отечественных, зарубежных, а также нахских языковедов;

- дать общее представление о подлежащем и сказуемом в современном ингушском языке;

- изучить проблему выделения прямого дополне-
Богатырева Aсиат Хаджи-Муратовна

Аспирант, Ингушский государственный университет bogatyreva.asiyat.92@mail.ru

Аннотация: В данной статье автором рассматриваются теории выделения главных членов предложения применительно к системе современного ингушского языка. Подвергается сомнению точка зрения лингвистов, согласно которой прямое дополнение выделяют как главный член предложения В современном ингушском языке. Полученные результаты показали ошибочным отнесения прямого дополнения в данном языке к главным членам предложения. Также на примерах показано чем может быть выражено подлежащее в ингушском языке.

Ключевые слова: ингушский язык, субъект, предикат, прямое дополнение, предложение, теории, члены предложения.

ния как главного члена предложения в современном ингушском языке.

Научная новизна заключается в том, что в научных трудах, существующих на данный момент, есть противоречия между исследователями касаемо вопроса отнесения прямого дополнения к главным членам предложения.

Итак, в истории языкознания известны три теории иерархии членов предложения. Согласно первой из них, сторонниками которой были О. Есперсен и Г. Гийом, существительное, которым выражается подлежащее в предложении, считается главной частью речи языка. А подлежащее, выраженное именем существительным, в соответствии с этим считается безусловно господствующим членом предложения [1, с. 43].

Аналогичная точка зрения находит подтверждение в логике понятий: имя означает субстанцию, тогда как глагол и прилагательное выражают акциденции, признаки субстанции и, значит, призваны предопределять имя.

Следующая (вторая) точка зрения, более распространенная в грамматической традиции, подразумевает равноправие двух главных членов предложения, а именно, 
подлежащего и сказуемого. Также вторая точка зрения подкрепляется логически, но уже логикой суждения: двум главным членам суждения - субъекту и предикату - в структуре предложения соответствуют два основных взаимно дополняющих члена предложения.

Этой точки зрения придерживаются отечественные лингвисты (А.А. Потебня, Ф.И. Буслаев, А.Х. Востоков, А.М. Пешковский, Ф.Ф. Фортунатов, А.А. Шахматов и другие).

Так, А.А. Потебня отмечал, что на современном этапе развития русского языка «для нас предложение немыслимо без подлежащего и сказуемого»... Двусоставным называется предложение, которое имеет две грамматические основы: подлежащее и сказуемое [2, с. 38].

Ф.И. Буслаев отождествляет подлежащее и предикат с субъектом и предикатом логического суждения. Исследователь видит разницу между этими логическими и грамматическими категориями в том, что в «логическом отношении второстепенные члены предложения не отделяются от ключевых и совместно с ними представляют логическое подлежащее или логическое сказуемое» [3, c. 52].

А.Х. Востоков считает, что: «Подлежащее - есть имя предмета, о котором рассказывается. Предикат есть глагол, или все то, собственно, что о предмете говорится» [4, с. 48].

Но А.А. Потебня выступал против отождествления подлежащего и сказуемого с субъектом и предикатом логического суждения. Он предложил идею: «Всякая знаменательная часть речи имеет возможность быть, смотря по контексту, предметом, о котором рассказывается в предложении» $[2$, с. 66].

Согласно учению А.А. Шахматова, в двусоставном предложении выделяются подлежащее и предикат. «Причем подлежащее, - поясняет А.А. Шахматов, - это главный член господствующего, а сказуемое - главный член зависимого состава...» [5, с. 30].

Ученые третьей теории иерархии членов предложения (Теньер Л.) считают, собственно, что глагол (сказуемое) - это безусловно господствующий член предложения.

Данная концепция делает упор на коммуникативный аспект предложения: главенство сказуемого подчеркивается тем, что как раз оно считается носителем предикативных категорий (время, модальность и др.) и выступает организующим узлом предложения: через глагол соотносятся иные члены предложения - подлежащее, дополнение, определение, обстоятельства.
Итак, в современном ингушском языке основу предложения составляют подлежащее и сказуемое. Подлежащее показывает объект, выполняющий действие, или человека, совершающего действие. В ингушском языке подлежащее может быть выражено существительным (ц1ердешаца), местоимением (ц1ерметтдешаца), самостоятельной формой прилагательного (ло1амеча белгалдешаца), числительным (таьрахьдешаца), самостоятельной формой причастия (ло1амеча причастеца) и т.д. Например:

БІарг бІарга mla а оттабаь къарвала гlертар ГІойберд - «Не отводя глаз от глаза, Гойберд [подл., выраж.сущ., им.п.] хотел оправдаться» [6, с. 118];

Кхоана экскурсе тхо а долх - «Завтра мы [подл., выраж.мест., им.п.] тоже идем на экскурсию» [6, с. 97];

Майрабараш ч1оагг 1а латар моастаг 1ашиа - «Храбрецы [подл., выраж. самост.ф.прилаг., им.п.] сражались сильнее с врагами» [6, с. 189];

Ломма хьунаг1а экскурсе воаг1ар ханнахьа кийчлелаш - Кто [подл., выраж. самост.ф.прич., им.п.] идет послезавтра на экскурсию подготовьтесь [6, с. 209].

Сказуемое - один из главных членов предложения, который обозначает действие субъекта или объекта. К примеру, Ваьхав миска, ваьхав г1ийла, г1ийла миска лоамаро, хиннад иун ц 1 а, даьсса, шийла - Жил [сказ., прош. вр., неперех.] бедный, жил [сказ., прош.вр., неперех.] худой, худой бедный горец [подл., выраж.сущ., им.п.], был [сказ., прош.вр., неперех.] дом у него, пустой, холодный $[6$, c. 136].

Исследователи нахских языков Н. Ф. Яковлев, А. И. Халидов, Ф. Г. Оздоева, М. А. Кульбужев, 3. М. Баркинхоева, Х. Б. Навразова, А. З. Гандалоева исследовали в своих трудах простое предложение, а также его типы и конструкции.

Н.Ф. Яковлев выделяет три главных члена предложения в ингушском языке: подлежащее, сказуемое, прямое дополнение. Также он выделил два типа подлежащих: продуктивное (переходное) и непродуктивное (непереходное) $[7$, с. 56].

По Н. Ф. Яковлеву, продуктивное подлежащее стоит в активном падеже и употребляется лишь только в переходном предложении. Это подлежащее выражает лицо или предмет, продуктивно деятельный, то есть такой, который исторически был непосредственным производителем (субъектом производства). В следствие этого при продуктивном подлежащем всегда может стоять прямое дополнение, то есть исторически название продукта или предмета труда, а впоследствии также объекта действия 
вообще.

По мнению автора, продуктивное подлежащее может стоять лишь при глагольном сказуемом: Хозача дешо Іургара лехь баьккхаб (пословича) - «Красивое слово [ им.сущ., выраж. подл. в эрг.п., ед.ч.] выманило змею из норы»;

Хозача дешо лакха лоам бошбаьб (пословица) -«Красивое слово [им.сущ., выраж. подл. в эрг.п., ед.ч.] растопило высокую гору»;

Дахчан пхьаро мебель ю - «Столяр плотник [им.сущ., выраж. подл. в эрг.п., ед.ч.] делает мебель»;

Нанас дулх кхехкаду/кхехко - «Мать [им.сущ., выраж. подл. в эрг.п., ед.ч.] варит мясо»;

Сесаго коч тег - «Жена [им.сущ., выраж. подл. в эрг.п., ед.ч.] шьет рубаху»;

Саго болх бу - «Человек [им.сущ., выраж. подл. в эрг.п., ед.ч.] работает (делает работу)»;

Аз книжка деш - «я [им.сущ., выраж. мест. в эрг.п., ед.ч.] книгу читаю»;

Вай колхозаша аре дика а оах, чехка ялат чу а дахь - «Наши колхозы [им.сущ., выраж. подл. в эрг.п., мн.ч.] хорошо пашут поле и быстро убирают хлеб» [7, с. 56-58].

В приведенных выше примерах подлежащее выступает как агенс: активный, обычно наделенный волей и сознанием, участник ситуации, расходующий собственную энергию в процессе деятельности. В первом, втором и восьмом предложениях подлежащее выступает как причина, т.е. участник (неодушевленный), который является причиной изменений состояния пациенса, а в третьем, четвертом, пятом, шестом и седьмом предложениях агенс выступает как активный участник ситуации, берущий на себя всю ответственность происходящего.

Следовательно, во всех случаях, когда в предложении подлежащее стоит в продуктивной форме (активном падеже) подразумевается прямое дополнение.

Непродуктивное подлежащее выражает лицо или предмет действия и при таком действии, которое не может иметь ни продукта труда, ни объекта вообще. Следовательно, непродуктивное подлежащее употребляется только в непереходном предложении и стоит в именительно-винительном падеже. В качестве сказуемого при нем употребляется непереходный глагол.

Таким образом, при именном сказуемом, а также при таком глагольном сказуемом, которое выражает состояние, может стоять только непродуктивное подлежащее:
Дахчан пхьар дахча да вахав - «Столяр плотник [им. сущ., выраж. подл. в им.п.,ед.ч.] пошел за дровами (принести древесину)»; Нани гlанда mla Іохайна ягla - «Мать [им. сущ., выраж. подл. в им.п.,ед.ч.] сидит на стуле» [7, с. 59].

Приведенные примеры показывают, что ряд глагольных сказуемых, выражающих не только состояние, но и настоящее действие, имеет при себе непродуктивную форму подлежащего.

Придерживаясь теории Н.Ф. Яковлева, ученые Ф.Г. Оздоева и М.А. Кульбужев в учебном пособии «Синтаксис ингушского языка» выделяют также три главных члена предложения: сказуемое, подлежащее, прямое дополнение. По их мнению, подлежащее и сказуемое составляют основу предложения. Сказуемое отвечает на вопросы фу ду? что делает? фу даьд? что сделал? фу дир? что сделано? фу дора? что делал? фу даьдар? Что сделал? фу дергда? что сделает? [8, с. 27-30].

Такой же точки зрения придерживается и 3.М. Баркинхоева, выделяя в ингушском языке пять конструкций: номинативная, эргативная, аффективная, генетивная, локативная; и три главных члена предложения [9, с.74; c.106].

Надо отметить, что «наличие эргативно построенного переходного предложения типологически объединяет структуры предложения всех иберийско-кавказских языков, но само выражение субъекта-подлежащего не во всех языках связано с употреблением именно эргативного падежа» [10, с. 86].

В эргативном типе ингушского предложения субъектное значение строго закреплено за эргативом, который может быть только подлежащим при финитном глагольном сказуемом. В современном ингушском языке финитное глагольное сказуемое в эргативном предложении только переходное. К примеру, Доккха диллача лаьво аргlе кІайлаяьккхар - «Выпавший большой снег застелил поле», где (сево?) лаьво «снег» - подлежащее в эргативном падеже; кlайлаяьккхар «застелил» - финитное глагольное сказуемое.

Но это не означает, что переходный глагол всегда имеет при себе морфологически выраженное прямое дополнение в форме именительного падежа.

Итак, выделение прямого дополнения как главного члена предложения связано с тем, что в современом ингушском языке нет винительного падежа. Как мы уже знаем в ингушском языке восемь падежей: именительный (ц1ера дожар), родительный (доала), дательный (лура), эргативный (дера), союзный (кечала), заключающий (хотталура дожар), местный (меттига дожар), срав- 
нительный (дустара дожар). Как мы видим, четвертым стоит эргативный падеж, а в русском языке в основном прямое дополнение выражается существительным в винительном падеже без предлога. Чуть ниже мы рассмотрим эргативный падеж на примерах.

А.И. Халидов, отмечая факт выделения прямого дополнения некоторыми лингвистами как главного члена предложения, пишет следующее: «Согласование в классе и числе не представляется, однако, серьезным и достаточным аргументом для включения прямого дополнения в число главных членов, особенно если учесть, что обычно классного и классно-количественного согласования предиката и прямого дополнения мы не наблюдаем - ввиду отсутствия классных показателей у большинства глаголов» $[11$, с. 127].

В связи с исследованием данной проблемы в нахских языках Х.Б. Навразова пишет, что: «Основная проблема, которая лежит в основе разногласий между кавказоведами при рассмотрении структуры предложения в эргативных кавказских языках, сводится к вопросу статуса прямого дополнения в иерархии членов предложения в эргативной конструкции предложения» [12, с. 56].

А.3. Гандалоева характеризует эту проблему следующим образом. Она пишет: «Прямое дополнение в иерархии членов предложения занимает все же не то пространство, которое ему отводится в грамматической традиции» $[13$, с. 98].

Таким образом, придерживаясь точки зрения А.И. Халидова, Х.Б. Навразовой, А.З. Гандалоевой мы устанавливаем лишь две главные члены предложения в современном ингушском языке, а именно, подлежащее и сказуемое. Рассмотрим примеры: Тенна дегlи доккха mангари дола Ахьти а вар латmаш базар mla - «C большим животом и толстым телом Ахти [им.сущ., им.п., ед.ч.]тоже стоял [сказ.,прош.вр., неперех.] на базаре»;

Тувлавала дагахь наха юккъе гІолла чутиллар из - «Чтобы потеряться [сказ.,наст.вр.] среди людей, он [им.п., ед.ч.] устремился [сказ.,наст.вр., неперех.] к толпе»;

Сурхотlара Алхасте гаьна яц - «От Сурхахов Алхасты [им.сущ., им.п.] недалеко»;

Истола mla уллар хоза баьццара къоалам - «На столе лежал [сказ.,наст.вр.] красивый зеленый карандаш [им.сущ., им.п., ед.ч.]»;

КІирвенна ший кІаьнка бІарахьежар да - «Пристально смотрел [сказ.,наст.вр., неперех.] отец [им.сущ., им.п., ед.ч.] на своего сына»;
Цкъа ше аьнначоа mlaра воалаш 1аьдал деце а, воlа бІарахьежача чун юхь йоагае карагІдаланцар Мандречоа - «Хотя Мандре [им.сущ., им.п., ед.ч.]всегда стоял [сказ.,прош.вр., неперех.] на своем сказанном слове, посмотрев на сына, не смог возразить [сказ.,наст.вр., неперех.] ему»;

Цу мехка вахаш хиннав Іалаьмате вlаьхий саг - «В этой стране жил [сказ., прош.вр., неперех.]один богатый человек [им.сущ., им.п., ед.ч.]» [14, с. 3-12 ].

Во всех этих примерах подлежащее большей частью ориентируется со сказуемым по признаку характера связи и способу лексико-морфологического выражения.

Также подчеркнем, что подлежащее в ингушском языке способно принимать формы двух падежей: номинативный (им.) и эргативный:

Ара сийрда малх хьеж - «На улице ярко светит солнце [им.сущ., выраж. подл. в им.п., ед.ч.]»; малх - подлежащее в именительном падеже фу? малх;

Сийрда хьежача малхо лаьтта дохьадаьд - «Ярко светящее солнце [им.сущ., выраж. подл. в эрг.п., ед.ч.]согрело землю»; малхо - подлежащее в эргативном падеже сево? малхо. Солнце выступает в роли агенса, который осуществляет действие.

Если мы сравним эти две конструкции, то заметим, что в первом случае подлежащее выступает как источник, а во втором случае - причина, т.е. участник (неодушевленный), являющийся причиной изменений состояния пациенса, а именно, пассивного участника ситуации, который претерпевает изменения в ходе не контролируемых им внешних воздействий. Что же касается сказуемого, в первом предложении глагол хьеж «светит» стоит в настоящем времени, непереходный, а во втором предложении глагол дохьадаьд «согрело» (наст.вр.) переходный.

Типология конструкций предложения тесно связана с типологией членов предложения, в рамках которой предлагаются идеи о неуниверсальности подлежащего и о разграничении языков в зависимости от того, какой тип информации выражается в структуре предложения в первую очередь: члены предложения, обычные роли участников ситуации, их статус с точки зрения уже знакомой или новой информации, отношение сообщаемого в предложении к участникам речевого акта - говорящему и слушающему и т.п.

Таким образом, исходя из вышесказанного, мы пришли к выводу, что существует грамматический и логический взгляд на конструктное членение предложения. Согласно логическому членению предложения в со- 
временном ингушском языке можно выделить пять конструкций предложения и три члена предложения. Этой точки зрения придерживаются Н.Ф. Яковлев, Ф.Г. Оздоева, М.А. Кульбужев, 3.М. Баркинхоева. Также отметим, что признание прямого дополнения третьим главным членом означает признание трехсоставности предложения.

Все второстепенные члены предложения в том числе и дополнения всегда входят в состав одного из двух главных членов двусоставного предложения. Во всех случаях присутствия классного экспонента у глагольного сказуемого прямое дополнение настоятельно просит от него согласования в классе и числе, переходный глагол согласуется лишь с прямым дополнением, согласование его с подлежащим исключено. В непереходных конструкциях, там, где глагольное сказуемое имеет классный показатель, он согласуется с подлежащим-номинативом.

Грамматическое членение предложения выделяет два главных члена предложения, а именно, подлежащее и сказуемое, также выделяют номинативную и эргативную конструкции предложения. Этой теории придерживаются А.И. Халидов, Х.Б. Навразова, А.З. Гандалоева.

Мы в данной статье, рассмотрев прямое дополнение как главный член предложения, выявили, что проблема выделения прямого дополнения связана с отсутствием в ингушском языке винительного падежа. Более детальное изложение средств и способов согласования главных членов предложения в системе синтаксиса современного ингушского языка будет составлять предмет наших дальнейших исследований.

\section{Список условных сокрашений}

им. п. - именительный падеж

эрг.п. - эргативный падеж

подл. - подлежащее

сказ. - сказуемое

им. сущ. - имя существительное

ед. ч. - единственное число

мн. ч. - множественное число

прош. вр. - прошедшее время

наст. вр. - настоящее время

неперех. - непереходный

перех. - переходный

гл. - глагол

прилаг. - прилагательное

прич. - причастие

мест. - местоимение

самост.ф. - самостоятельная форма

нахские языковеды - исследователи нахских языков

ЛИТЕРАТУРА

1. Есперсен 0. Философия грамматики. Издательство: «ЛКИ», 2006.310 с.

2. Потебня А.А. Из записок по русской грамматике. Том I-II. Харьков, 2012. 238 с.

3. Буслаев Ф.И. Опыт исторической грамматики русского языка. Ч. ІІ. М., 2013. 213 с.

4. Востоков А.Х. Русская грамматика по начертанию его же сокрашенной грамматики полнее изложенная. СПб., 2011. 321 с.

5. Шахматов А.А. Синтаксис русского языка. Ленинград, Учпедгиз, 1941. 245 с.

6. Оздоев І.И., Оздоев И.Р. Грамматика ингушского языка. Магас, 2018. 320 с.

7. Яковлев Н.Ф. Синтаксис ингушского литературного языка. Под редакцией М.Е. Алексеева. М.: Академия, 2000. 472 с.

8. Оздоева Ф.Г., Кульбужев М.А. Синтаксис ингушского языка (Учебное пособие). Магас, 2006. 86 с.

9. Баркинхоева 3.М., Хайрова Х.Р. Проблемы синтаксиса ингушского языка. Нальчик, 2007. 228 с.

10. Халидов А.И. Очерки истории и типологии нахских языков. Грозный: ГУП «Книжное издательство», 2008. 413 с.

11. Халидов А.И. Типологический синтаксис чеченского простого предложения. - Нальчик. Издат.центр «Эльфа», 2004. 345 с.

12. Навразова Х.Б. Синтаксис чеченского простого предложения. Грозный, 2004. 215 с.

13. Гандалоева А.З. Актуальные вопросы синтаксиса ингушского простого предложения. Грозный, 2011. 129 с.

14. Зязиков Б.Х. Девять дней из жизни героя (Турпала вахарцара ийс ди). Повесть.Саратов: Региональное Приволжское издательство, 2012.156 с.

( Богатырева Асиат Хаджи-Муратовна (bogatyreva.asiyat.92@mail.ru).
Журнал «Современная наука: актуальные проблемы теории и практики» 